7. Child Lang. 29 (2002), 783-8I I. (C) 2002 Cambridge University Press

DOI : I0.I0I7/So30500090200538X Printed in the United Kingdom

\title{
Going, going, gone: the acquisition of the verb 'go'*
}

\author{
ANNA L. THEAKSTON \\ University of Manchester \\ ELENA V. M. LIEVEN \\ Max Planck Institute for Evolutionary Anthropology, Leipzig \\ JULIAN M. PINE \\ University of Nottingham \\ CAROLINE F. ROWLAND \\ University of Liverpool \\ (Received 20 Fuly 2000. Revised 10 February 2002)
}

\begin{abstract}
This study investigated different accounts of early argument structure acquisition and verb paradigm building through the detailed examination of the acquisition of the verb Go. Data from I I children followed longitudinally between the ages of $2 ; 0$ and 3 ; 0 were examined. Children's uses of the different forms of $G o$ were compared with respect to syntactic structure and the semantics encoded. The data are compatible with the suggestion that the children were not operating with a single verb representation that differentiated between different forms of Go but rather that their knowledge of the relationship between the different forms of $G o$ varied depending on the structure produced and the meaning encoded. However, a good predictor of the children's use of different forms of $G o$ in particular structures and to express particular meanings was the frequency of use of those structures and meanings with particular forms of $G o$ in the input. The implications of these findings for theories of syntactic category formation and abstract rulebased descriptions of grammar are discussed.
\end{abstract}

[*] We would like to thank all the families who took part in the research reported here. Also, thanks to two anonymous reviewers for their helpful comments on an earlier draft of this paper. This research was funded by the Economic and Social Research Council, Grant Numbers Rooo236393 and Rooo2379II. Address for correspondence: Anna L. Theakston, Department of Psychology, University of Manchester, Oxford Rd., Manchester, Mr 3 9PL, UK. tel: + 44 (I6I) 275-2600. fax: + 44 (I6I) 275-2588. e-mail: theaksto@psy.man.ac.uk

783 


\section{INTRODUCTION}

To understand how children attain adultlike verb use, two central questions must be answered. First, how do they form verb representations that allow them to use a verb in different sentence structures? Second, how do they acquire the grammatical systems for marking tense and agreement in a language necessary for the correct use of inflected verb forms? To explore these questions, we must first consider how this information may be represented in the adult grammar.

Verb semantics and syntactic structure representations in the adult grammar

The question of how verb meaning is represented in the adult lexicon is the subject of much debate (e.g. Levin \& Hovav, I995), in particular how variations in verb meaning, e.g. 'I sneezed a napkin off the table' vs. 'I sneezed'; Goldberg, I 995, are represented. Croft ( I 998) outlines four models of the adult lexicon concerned with this question: ( I) the independent entries model, where the two meanings are stored as independent lexical items with no relation between them, (2) the polysemy model, where the two meanings are stored independently, but speakers recognise a semantic link between them, (3) the derivational model, where the prototypical meaning is stored in the lexicon, but the second meaning is derived via the application of a lexical rule, and (4) the pragmatic model, where the central meaning is stored in the lexicon, but additional meanings are computed from general cognitive principles relevant to the specific context of use.

Generative approaches typically assume that either a single lexical entry is stored for each verb and alternative meanings are derived by applying general rules (e.g. Levin \& Hovav, I995), or multiple but unrelated entries are stored to represent different meanings (e.g. Pinker, I989). In many models alternative meanings have no status in the lexicon but rather are computed 'on the fly' (Croft, I 998: i 53). In contrast, constructivist models assume polysemy in representation (Langacker, I987, I99 I ; Croft, in press $b$ ). Lexemes are stored multiple times in a distributional network to encode different meanings, with links between entries made on the basis of phonological, semantic, or distributional similarity. Two central differences between these approaches are the constructivist assumptions that in the adult grammar, incorporating both idiomatic and more productive utterances, ( I) whole phrases and individual words are stored as units in the lexicon, and (2) speakers have grammatical knowledge stored at many different levels of abstraction. Frequently used constructions may be stored as units that can be retrieved as lexical wholes, as well as being exemplars of a more abstract construction. Thus, although adults have access to abstract grammatical representations, much of adult language use may be tied to frequently 
produced words and phrases stored as units in the speaker's lexicon. For example, adults are thought to have an abstract representation of the concepts Subject, Auxiliary, and Verb, but differences in the phonological reduction patterns in the production of the phrase I don't know (e.g. I dunno) suggest that whole phrases are often retrieved as single units (Bybee \& Scheibman, I999). Which phrases are stored as units is determined by type and token frequency of use.

This raises an important issue in language acquisition. If children first acquire frequent phrases that are stored as units in the adult lexicon, it is unclear whether they (a) have access to the underlying grammatical structure, or (b) initially learn whole phrases and only later determine their grammatical structure.

Verb representations and the use of inflection in the adult grammar

Generativists regard the use of inflection as a formal syntactic operation, and assume that adult speakers operate with a single lexical entry for individual verbs. Only irregular forms are stored in the lexicon occupying a cell in the inflectional paradigm for that verb (Marcus, Pinker, Ullman, Hollander, Rosen \& Xu, I992; Pinker, I 984). The full range of verb forms is computed in the same way for every meaning of that verb, by either the application of general inflectional rules, or the inheritance of irregular forms from an existing verb meaning (Pinker, I 994: I 42). Constructivists, in contrast, claim that inflectional morphemes have semantic and phonological content, and are stored in the lexicon. Different inflected verb forms therefore consist of different combinations of meanings, and have different representations in the lexicon (Langacker, I 99I). Whether an inflected verb form is stored as a unit or computed from an abstract schema is determined by the type and token frequencies of particular combinations (Bybee, I995), and might differ according to the specific construction in which that form appears.

The acquisition of the verb lexicon

The question of how children acquire the range of meanings associated with specific verbs and how this interacts with their acquisition of inflection is complex. This paper is a longitudinal study of the acquisition of the verb Go in the speech of I I English-speaking children between the ages of 2 ; 0 and 3 ;.$^{1} \mathrm{Go}$ is acquired early (Tomasello, I 992), is very frequent in early speech (Bloom, Miller \& Hood, I 975 ; Clark, ı 978 ; Naigles \& Hoff-Ginsberg, I 998),

[I] Terminology: throughout this paper, the form 'Go' (upper case ' $G$ ') will be used to refer to the verb 'Go' as a whole while 'go' (lower case ' $\mathrm{g}$ ') will be used to refer specifically to the stem/non-inflected form of the verb; 'structures' will be used to refer to the syntactic structures listed in Table I, 'meanings' will be used to refer to the semantic categories listed in Table 2, and the phrase 'different forms of Go' will be used to refer to the forms go, going/gonna, goes, gone, and went.

785 
and can be used in different syntactic structures and to encode different MEAnings (see Tables I and 2). The Different FORMs of Go (go, going/gonna, goes, gone, went) are easily identified making it possible to examine children's understanding of the relation between them. The present study has two aims; first to provide detailed documentation of the use of $G o$ over a long period of development, and second, to use the data to investigate whether generativist and constructivist approaches to early verb learning can be distinguished empirically. Before presenting the data, we will consider what predictions can be derived from these approaches.

The acquisition of different meanings of Go. Although generativists assume that children's early speech reflects the workings of an abstract grammar, they may argue that children will not have lexical rules governing argument structure alternations until they have acquired a large number of verbs. Initially, different verb meanings may be stored as separate lexemes from which the verb's argument structure is projected (Pinker, I 989), and may be acquired separately. No specific predictions follow regarding their order of acquisition. Constructivists assume children's grammatical knowledge initially consists of constructions based on high frequency forms in the input (Tomasello, I992; Pine, Lieven \& Rowland, I998). Only when they have acquired a number of exemplars of a particular construction will they build the more general schemas, such as the transitive construction (Akhtar \& Tomasello, I 997), that underlie adult language use. Children should first acquire frequently modelled meanings of $G o$ as lexically-specific constructions, and will only begin to build links between different meanings of $G o$ later in development when they have acquired a number of forms of $G o$ with a number of structures or meanings.

These two positions cannot be distinguished empirically as both predict that initially, different MEANINGS of $G o$ will exist independently, and nativists make no predictions regarding order of acquisition. Can these approaches be distinguished in terms of the early use of the different ForMs of Go?

The acquisition of the different forms of Go. The use of inflected verb forms is often taken as evidence that children have an abstract knowledge of tense and agreement. However, few researchers make specific predictions regarding the process by which children recognise that different lexemes are exemplars of a single verb. This question becomes more complex when considering verbs with multiple meanings.

Two generativist approaches to the acquisition of inflection will be considered. The first assumes that children have acquired the knowledge necessary to distinguish between different forms of $G o$ before they enter the two-word stage, and produce utterances like he go and he goes as optionally inflected forms of Go (Wexler, r 994, r 998). Thus, from the earliest stages, children have the knowledge necessary to produce all forms of $G o$ with any structure or meaning used with another form of $G o$. The second approach 
assumes a more gradual pattern of acquisition (Pinker, I984; Radford, I 990). Children may initially produce different forms of $G o$ with different structures or meanings without recognizing the relation between them. However, given the assumption that a verb's syntax is projected from its semantics, it seems reasonable to assume that once children have produced two forms of $G o$ in the same structure, they will recognise a semantic relation that will enable them to enter them in a single paradigm. The phonological similarity between paradigms associated with individual meanings or structures should also facilitate the construction of a unified verb paradigm. Together, these processes will rapidly enable children to use any form of $G o$ with any structure or meaning used with other forms of $G o$.

From a constructivist perspective, children do not initially have a knowledge of inflection, nor are they expected to rapidly acquire verb-general inflectional schemas. Instead, the acquisition of different forms of Go with different structures or meanings will reflect their frequency of use in the input. As the relative frequency of forms of $G o$ is likely to differ across constructions, it may take time for children to develop the knowledge necessary to produce all forms of $G o$ with all structures and meanings used with $G o$.

It should be possible to distinguish empirically between generativist and constructivist approaches to the development of verb paradigms. From a generativist perspective, only minimal overlap in the structures or meanings found with different forms of $G o$ is needed before children have the knowledge necessary to build a verb paradigm. Although the input frequency of different forms of $G o$ might influence their initial acquisition, once acquired, their frequency of use with different structures or meanings in the input should not affect children's ability to produce them all with any structure or meaning acquired with Go. From a constructivist perspective, the development of a general verb paradigm available for use across different structures and meanings will be a much lengthier process because it depends on the accumulating type and token frequencies of different forms in different constructions. Therefore, children's use of different forms of Go will be limited, and the acquisition of individual forms with specific structures and meanings will reflect the frequency of those forms in those constructions in the input.

Issues of sampling. Although generativist approaches should predict that children will produce the different forms of $G o$, once acquired, with all structures and meanings used with $G o$, the actual likelihood that children will produce these structures and meanings with different forms of $G o$ will be determined by a combination of their grammatical knowledge, the preferred forms of expression in the language, ${ }^{2}$ and the context in which speech is

[2] Some structures are fully grammatical, but nevertheless rarely appear in adult speech. 
sampled. While the absence of a specific structure or meaning with different forms of $G o$ in children's speech might mean that they have not acquired that structure or meaning with those forms of $G o$ and have a lexically-specific knowledge of syntax, it might instead reflect the preferred forms of expression. Furthermore, although constructivists predict that frequently modelled forms in the input will be acquired earlier by children than low frequency forms, this pattern of results could reflect sampling considerations. Children with adultlike grammatical knowledge may produce high frequency forms from the input earlier in sampled speech over the course of development than lower frequency forms.

Given these considerations, we cannot distinguish empirically between the different approaches with respect to the order of acquisition or the generalization of use of different forms of $G o$ across different structures or meanings without both an exhaustive speech sample (to avoid sampling problems) and experimental studies (to elicit the use of structures that are rarely found in spontaneous speech). Further analyses are necessary. The method adopted here is to compare verb use in specific syntactic structures (e.g. $\mathrm{V}+\mathrm{PP}$ ) in matched samples of mothers' and children's speech, taking into account the acquisition of specific lexemes. Using matched samples removes the possibility that children's verb use appears more limited because they speak less than adults, and ensures that if adults and children operate with the same underlying grammatical knowledge, the likelihood that particular verb uses will appear in the children's and adults' speech is equal. Moreover, it is within specific syntactic structures that constructivists would first expect generalization between forms of $G o$ to occur (constructionspecific vs. more general paradigms).

To summarize, the aims of the present study are to examine to what extent ( I) uses of different forms of $G o$ are syntactically or semantically distinct, (2) children generalize knowledge of structures and meanings across different forms of $G o$, and (3) children's use of different forms of Go differs from their use in the input. The following predictions were derived:

Constructivist. ( I) Children will learn high frequency constructions from the input with individual forms of $G o$ earlier in development than low frequency constructions, (2) little generalization between forms of $G o$ will occur, reflecting the fact that they are initially associated with different constructions, and (3) in specific constructions, the use of particular complements in the children's speech will be less diverse than in the input (e.g. fewer different prepositions occurring in prepositional complements in the children's speech than in the input), reflecting the greater degree of abstraction underlying adult speech.

Generativist. ( I) From early in development, children will have the knowledge needed to produce all forms of $G o$ with all available structures and meanings, but high frequency constructions found in the input will be 
TABLE I. Syntactic structures used with the verb 'Go'a

\begin{tabular}{|c|c|c|}
\hline I. & $\mathrm{V}(\mathrm{Go})+\mathrm{adverb}$ & I go here; He went fast \\
\hline 2. & $\mathrm{~V}(\mathrm{Go})+\mathrm{PP}$ & It goes in there \\
\hline 3 . & 'Go'+ infinitive/gerund & He's going to hit it; I'm going shopping \\
\hline 4. & 'Go' within infinitival complement & I want to go home \\
\hline 5 . & Other two verb utterances & Let me go out; I'll go and put it on \\
\hline 6. & $\begin{array}{l}\text { Yes-no question } \\
\text { (with subject auxiliary inversion) }\end{array}$ & Are you going? \\
\hline 7 . & Tag question ${ }^{\mathrm{b}}$ & He's going to the shops, isn't he? \\
\hline 8. & Wh-question & Where's it gone? \\
\hline 9 . & 'Go' with no complement & It's gone; He's going \\
\hline IO. & $\begin{array}{l}\text { Reversed word order } \\
\text { (all cases where word order is reversed) }\end{array}$ & There you go; Off we go \\
\hline
\end{tabular}

a In declaratives, auxiliaries and auxiliary-like verbs followed by an -ing participle (e.g. stop going, keep going) were ignored for the purpose of utterance categorization. These utterances were coded as single verb utterances rather than two verb utterances.

b Tag questions were coded separately because they create a third type of question, and involve coordinating knowledge of the person marking in the main clause (which can be encoded on the main verb - it goes there, doesn't it, or on an auxiliary it does go there, doesn't $i$, and thus interacts with knowledge of marking on the main verb) with the appropriate auxiliary form for use in the tag. However, there were only a very small number of tag questions produced by any of the children so the decision to code these utterances in a separate category does not impact on the overall analysis.

sampled earlier than low frequency constructions, (2) there will be little evidence of generalization between forms of $G o$ if that reflects the preferred forms of expression in the language, and (3) in specific constructions, the diversity of use of particular complements will be similar in the children's speech and the input, reflecting the abstract nature of the grammar underlying both adult and children's speech.

Note that it is difficult to empirically differentiate the two approaches with respect to predictions (I) and (2), while prediction (3) ought to be testable. The difficulty in empirically distinguishing between these two seemingly diametrically opposed approaches will be taken up again in the Discussion.

METHOD

Subjects

The participants were eleven of twelve children who took part in a longitudinal study of early language development. One child did not produce all forms of $G o$ and was excluded. The children were from predominantly middle class, monolingual English-speaking families and were recruited through newspaper advertisements and local nurseries. They were firstborns and were cared for primarily by their mothers. At the beginning of the 
study the children ranged in age from I $; 8.22$ to $2 ; 0.25$ with MLUs ranging between $\mathrm{r} .06$ to 2.22 in morphemes. The Manchester corpus (Theakston, Lieven, Pine \& Rowland, 200I) is available on the CHILDES database (MacWhinney, 2000).

\section{Procedure}

The children were audiotaped in their homes for an hour on two separate occasions in every three week period for one year. They engaged in normal everyday interaction with their mothers. The data were orthographically transcribed using the CHILDES system (MacWhinney \& Snow, I990; MacWhinney, 2000).

\section{The children's speech corpora}

Using the CLAN programmes (MacWhinney \& Snow, I990; MacWhinney, 2000) the transcripts were searched for all instances of the different forms of Go (go, going, gonna, goes, gone, went). Self-repetitions, imitations, incomplete or partially intelligible utterances and routines (e.g. nursery rhymes, counting) were excluded from the children's corpora. The data for each child were divided into eight time periods of approximately six weeks, seven comprising four one-hour recordings and the last time period comprising six one-hour recordings.

Syntactic development. For each form of Go, the utterances were coded according to the structures listed in Table I. One tenth of the children's utterances taken equally across the children, half taken from the beginning and half from the end of the study, were coded by a second investigator. Inter-coder reliability measured using Cohen's kappa resulted in a coefficient of 0.97 . For each form of Go, children were assumed to have acquired a particular structure once they had produced two utterances with that form of $G o$ in that structure (e.g. go away + go in $=g o+A d v$; goes in that door + goes in there $=$ goes $+P P)$.

Semantic development. For each form of Go, the utterances were coded according to the meanings listed in Table 2. Where utterances were ambiguous, linguistic context (i.e. preceding and following utterances) was used to determine the child's meaning. One tenth of the children's utterances taken in equal numbers from each child, half from the beginning and half from the end of the study, were coded by a second investigator. Inter-coder reliability measured using Cohen's kappa resulted in a coefficient of 0.87 . For each form of $G o$, children were assumed to have acquired a given meaning once they had produced two utterances with that form of $G o$ with that meaning (e.g. it's going + going to hospital $=$ going/movement; that went bang + it went bang $=$ went $/$ sound $)$.

Lexical diversity. To establish the extent to which children generalized use 
TABLE 2. The semantic senses encoded by the verb 'Go'

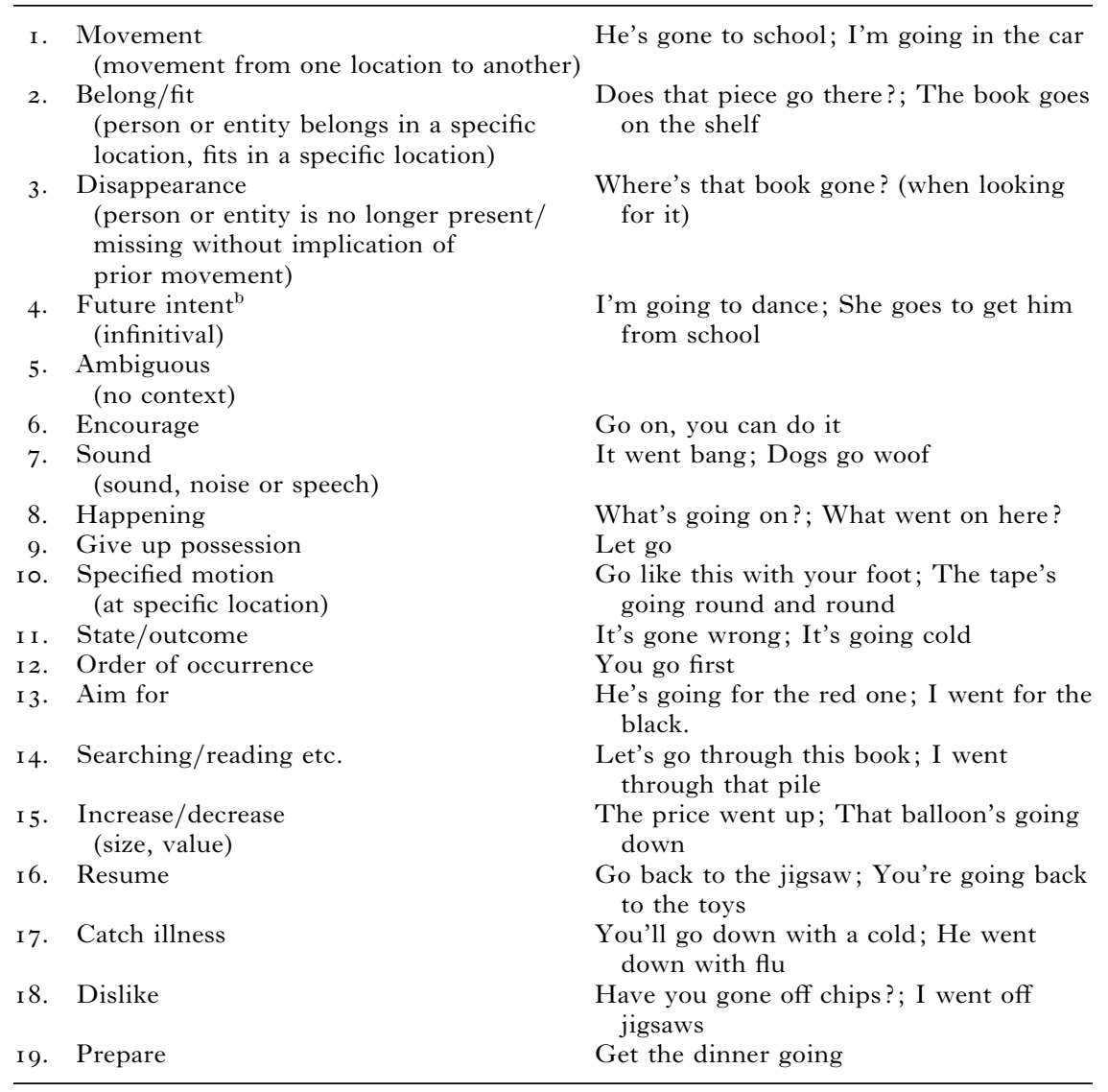

${ }^{a}$ All utterances with reversed word order (e.g. there you go) were excluded from the semantic analyses because they were frequently ambiguous in their meaning. In all cases, surrounding utterances were examined to provide contextual information to inform the semantic classification. (e.g. The balloon's going down would only be coded as Increase/decrease rather than Motion, if it was clear that the utterance referred to the deflation of the balloon, and not the movement of the balloon, for example, down the stairs.)

b There is an issue with respect to the semantics encoded by infinitival structures. While the progressive verb form 'going' has, over time, grammaticised and can be used to express intent or future events without necessarily encoding any form of movement (Bybee et al., I 994) (e.g. I'm going to think about it), other verb forms have retained the reference to movement in this structure (He's gone to think about it; I went to think about it). Some uses of going can also be ambiguous in this respect and may refer to either movement or a future event (e.g. I'm going to open the door). The lack of detailed contextual information meant it was impossible to differentiate these meanings, therefore for the purposes of this study, all infinitival utterances are classified as examples of the semantic category 'Future intent'. 
of the individual lexical items associated with specific structures (e.g. the PPs used in $\mathrm{V}+\mathrm{PP}$ utterances) across different forms of $G o$ used in those structures, and to compare the children's use with use in the input, the range of lexical items produced in particular structures with each form of Go was documented. The structures examined were PP complements, infinitival complements and Wh-questions.

\section{The mothers' speech corpora}

The mothers' data were searched for all exemplars of $G o$ and the children's data were compared with the input for the use of different structures and meanings, and for the diversity of use of lexical forms within specific structures.

Syntactic structures. It was not possible to directly compare the relative proportional use of different structures in the children's speech with their use in the input because the mothers produce a much greater proportion of complex structures (e.g. two clause utterances, questions) than the children, even though it is reasonable to assume that children learn to produce simple structures (e.g. $\mathrm{V}+\mathrm{PP}$ ) from many possible sources in the input including complex sentences. Therefore, for purposes of comparison with the children's speech, the mothers' data from the first eight tapes were coded for a subset of the structures listed in Table I $(\mathrm{V}+\mathrm{Adv}, \mathrm{V}+\mathrm{PP}, G o$ as infinitive, Yes/No question, Wh-question, no complement, and word order reversals). Individual phrases with $G o$, rather than whole utterances, were coded. Questions were coded twice, once as a Yes/No or Wh-question, and once according to the complement of the verb Go. The proportional use of each structure was then calculated.

Verb semantics. For purposes of comparison with the children's speech, the mothers' data from the first eight tapes were coded according to the meanings listed in Table 2. The proportional use of each meaning was then calculated.

Lexical diversity. Two sets of corpora were selected for the purposes of comparison with the children's speech. First, to compare lexical diversity in the children's speech and in the input, each mother was matched with her child for the number of utterances produced with each form of $G o$ for the whole year. The mothers' utterances were taken consecutively beginning from the first transcript until the correct number of utterances were selected. On four occasions, the total number of maternal utterances available for a particular form of $G o$ was less than the number of utterances produced by her child for that form. Second, to investigate whether frequency in the input was related to the order of acquisition of particular lexical forms in the children's speech throughout the year, the input data from the first eight tapes were examined. 


\section{Correlation analyses}

All correlational analyses are based on the mean use of particular structures or meanings with different forms of $G o$ in the children's speech and in the input. In each case, 55 pairwise correlations were conducted, reflecting all possible comparisons between the I I mothers or children, to establish whether similarities existed between mothers or children. These correlations show that the use of particular structures or meanings is similar across mothers and across children, thus justifying the decision to report mean values. ${ }^{3}$ A summary of the 55 correlations conducted is given with each analysis detailing the number of items included in each correlation, and the proportion of correlations where the correlation coefficient was above a given value.

\section{RESULTS}

The proportional use of the different forms of Go

Table 3 shows that there are differences in the children's proportional use of each form of Go. The form go accounts for the greatest proportion of the data, going and gone are relatively frequent, but goes and went account for a small proportion of the data. ${ }^{4}$

This is unsurprising as goes and went are probably relatively infrequent in adult language while go is the most common form to be used as the verb complement of other verbs (e.g. I want to go home) and thus accounts for a greater proportion of the data. ${ }^{5}$ The question of interest is whether the forms of $G o$ differ with respect to the structures and meanings with which they appear as well as in their frequency of use.

\section{Syntactic development}

Differential use of syntactic structure. Only those structures produced by at least $\mathrm{s} 0$ of the children were included in the following analyses. From Table I, these were (I) V+adverb, (2) V+PP, (3) infinitives and gerunds, (5) two-

[3] For each comparison between the mothers and children's speech where pairwise correlations are reported, individual dyad analyses were also carried out to check whether relationships observed in the combined data were also found between individual mothers and their children. For clarity of presentation, and due to space limitations, the mean values are reported, but in all cases, a minimum of 9 of the $\mathrm{I}$ I individual dyad correlations were significant.

[4] There was only a single instance of overregularized goed in the entire corpus (Anne, tape $6, a \xi$ goed $u p$ ). As it is difficult to determine the meaning of this utterance (even taking into account the linguistic context), and Anne did not produce any further exemplars of goed, nor any exemplars of the irregular past tense form went until much later in the study (tape 2I), it is unclear how this apparent use of goed relates to other forms of Go. This utterance was not analysed further.

[5] Although other forms of $G o$ can also be used as the complement of other verbs (e.g. I like going home), utterances of this type were exceedingly rare in the data. 
THEAKSTON ET AL.

TABLE 3. The proportional use of each form of ' $\mathrm{GO}$ '

\begin{tabular}{|c|c|c|c|c|c|c|}
\hline & \multirow{2}{*}{$\begin{array}{l}\text { Number of } \\
\text { utterances }\end{array}$} & \multicolumn{5}{|c|}{ Proportional use of each form of ' $G o$ ' } \\
\hline & & go & going & goes & gone & went \\
\hline Anne & I००8 & $53 \cdot 7$ & $25 \cdot 8$ & $5 \cdot 2$ & I $4 \cdot 8$ & 0.6 \\
\hline Aran & I 029 & $63 \cdot I$ & I $3 \cdot 2$ & $3 \cdot 8$ & I 6.0 & $3 \cdot 9$ \\
\hline Becky & 830 & $5 \mathrm{I} \cdot \mathrm{I}$ & $30 \cdot 7$ & $3 \cdot 9$ & I 3.0 & $\mathrm{I} \cdot 3$ \\
\hline Carl & 1426 & $5 \mathrm{I} \cdot \mathrm{I}$ & $30 \cdot 7$ & $2 \cdot 4$ & I $3 \cdot 2$ & $2 \cdot 6$ \\
\hline Dominic & 698 & $47^{\circ} \mathrm{I}$ & $28 \cdot \mathrm{I}$ & $\mathrm{I} \cdot \mathrm{O}$ & $22 \cdot 5$ & $\mathrm{I} \cdot 3$ \\
\hline Gail & 753 & $49 \cdot 3$ & $3 I \cdot 3$ & $2 \cdot 4$ & I 5.4 & $\mathrm{I} \cdot 6$ \\
\hline Joel & 527 & $49^{\circ} 7$ & $36 \cdot 6$ & $2 \cdot I$ & 10.4 & $\mathrm{I} \cdot \mathrm{I}$ \\
\hline John & 373 & $68 \cdot 9$ & $8 \cdot 0$ & $5 \cdot 6$ & I 5.8 & $\mathrm{I} \cdot 6$ \\
\hline $\mathrm{Liz}$ & 687 & $39^{\circ} \circ$ & $34^{\circ} 6$ & $4 \cdot 9$ & I 9.9 & $\mathrm{I} \cdot 5$ \\
\hline Nicole & 406 & $5 \mathrm{I} \cdot 5$ & $23 \cdot 6$ & $3 \cdot 2$ & 20.9 & 0.7 \\
\hline Warren & I 3 IO & $62 \cdot 7$ & I $6 \cdot 9$ & $5 \cdot 6$ & $\mathrm{I} 4 \cdot 4$ & 0.4 \\
\hline Mean & $822 \cdot 5$ & $48 \cdot 9$ & $23 \cdot 3$ & $3 \cdot 3$ & I 4.7 & $\mathrm{I} \cdot 4$ \\
\hline
\end{tabular}

TABLE 4. The mean proportional use of syntactic structures produced by $\mathrm{IO}^{+}$ children with each form of 'Go'

\begin{tabular}{lrrcrcrr}
\hline & Adv. & PP & $\begin{array}{c}\text { Infinitive/ } \\
\text { gerund }\end{array}$ & $\begin{array}{c}\text { Two } \\
\text { verb }\end{array}$ & $\begin{array}{c}\text { Yes-no } \\
\text { question }\end{array}$ & $\begin{array}{c}\text { Wh- } \\
\text { question }\end{array}$ & $\begin{array}{c}\text { No } \\
\text { complement }\end{array}$ \\
\hline go & $28 \cdot \mathrm{I}$ & $27 \cdot 9$ & $\mathrm{I} 4 \cdot 8$ & $\mathrm{I} \cdot 6 \cdot 6$ & $3 \cdot 6$ & $5 \cdot 7$ & $8 \cdot 2$ \\
going & I $3 \cdot 2$ & $24 \cdot \mathrm{I}$ & $45 \cdot 9$ & $2 \cdot 5$ & $\mathrm{I} \cdot 5$ & $4 \cdot 5$ & $8 \cdot \mathrm{I}$ \\
goes & $40 \cdot 3$ & $36 \cdot 9$ & $0 \cdot 3$ & $6 \cdot 3$ & $0 \cdot 4$ & $6 \cdot 9$ & $7 \cdot 2$ \\
gone & $6 \cdot \mathrm{I}$ & $8 \cdot 8$ & $2 \cdot 3$ & $\mathrm{I} \cdot 6$ & $0 \cdot 4$ & $32 \cdot 8$ & $47 \cdot 8$ \\
went & $30 \cdot 0$ & $54 \cdot 6$ & $2 \cdot 3$ & $8 \cdot \mathrm{I}$ & 0 & $\mathrm{I} \cdot 7$ & $2 \cdot 4$ \\
\hline
\end{tabular}

verb utterances (excluding infinitivals), (6) Yes-no questions, (8) Whquestions and (9) no complement utterances. Word order reversals ( Io) were excluded because although in principle, this structure is available for use with all forms of $\mathrm{Go}, 99.8 \%$ of the children's utterances were with go or goes (there was only one exception), and therefore they do not provide a useful indicator of children's productive knowledge of syntax. To allow comparison across forms of $G o$ with respect to the relative use of each structure, Go within infinitival complement utterances (4) were also excluded from this analysis. This structure is highly frequent with go (459 examples overall) but is produced only once by each of four children with any other form of $G o$, all of which are grammatically incorrect (e.g. I need going). Although other structures are also ungrammatical with some forms of $G o$ (e.g. Wh-questions of the form Where's $X$ goes/went), all other structures were produced with at least four forms of $G o$ and were included in the analyses.

Table 4 shows the mean proportional use of each structure with each form of $G o(N=35: 5$ forms of $G o \times 7$ structures; $69 \%$ of the correlations were 
above 0.60 ). The data suggest that there are differences between the forms of Go with respect to their mean proportional frequency of use in these structures. The most frequent forms used with infinitival complements are go and going, goes is the most frequent form in adverb structures, gone is the most frequent form in Wh-questions and no complement structures but the least frequent form in adverb and PP structures while went is the most frequent form in PP structures. Thus, the least frequent forms, goes, gone and went, are not just less frequent than go and going but are also used in different structures.

Given these differences between forms of $G o$, it is unclear whether the children have adultlike grammatical knowledge and can use the different forms in a range of structures, or whether the children's knowledge is of a more limited nature and related only to individual forms of Go. The mean proportional use of structures with different forms of $G o$ in the children's speech was compared with their mean proportional use in the input $(N=30$ : 5 forms of $G o \times 6$ structures; $93 \%>0.70)$. The correlation was significant $(r=0.86, d f=28, p<0.00 \mathrm{I})$ showing that there is a strong relationship between use of individual forms of $G o$ in particular structures in the input and in the children's speech.

Order of acquisition of syntactic structure. Overall, the children's proportional use of structures with different forms of $G o$ closely resembles adult use, but it is not clear if this provides an accurate representation of their knowledge across the whole year. The mothers use all forms of $G o$ in all structures from the beginning of the study (tapes $\mathrm{I}-8$ ), but the children may take time to acquire the structures used with each form of $G o$. To examine this possibility, structures were ranked according to the time period when they were acquired for each child with each form of Go. Table 5 shows the mean rank order of acquisition of structures with each form of $G o(N=35$ : 5 forms of $G o \times 7$ structures; $84 \%>0.70$ ) and the approximate time period in weeks between the start of the study and the acquisition of each form in each structure.

There is a considerable delay between the first use of a structure with one form of $G o$ and its use with the full range of available verb forms. For example, go is the first form used with adverb complements, going is used in this structure 12 weeks later, while goes and gone are produced approximately 24 weeks later than go. In contrast, the less frequent form gone is the first produced in Wh-questions and no-complement structures, but there are then considerable and differing time periods before other forms of $G o$ are used in these structures.

The data show that the differences in the proportional use of each structure across different forms of $G o$ are reflected in the time at which each form is acquired in each structure. The children show little evidence that they are able to produce all the forms of $G o$ they have acquired in all the structures 
THEAKSTON $E T A L$.

TABLE 5. The mean rank order of acquisition of syntactic structures produced by $\mathrm{IO}^{+}$children $^{\mathrm{a}}$

\begin{tabular}{|c|c|c|c|c|c|c|c|}
\hline $\mathrm{Wk}^{\mathrm{b}}$ & Adv. & PP & $\begin{array}{l}\text { Inf. \& } \\
\text { gerund }\end{array}$ & $\begin{array}{l}\text { Two } \\
\text { verb }\end{array}$ & $\begin{array}{l}\text { Yes-no } \\
\text { qu. }\end{array}$ & Wh-qu. & $\begin{array}{c}\text { No } \\
\text { complement }\end{array}$ \\
\hline I-6 & & & & & & & gone \\
\hline & go & $g_{0}$ & & & & & \\
\hline $7^{-12}$ & & & & & & gone & go \\
\hline $\mathrm{I} 3-18$ & & & go & & & & going \\
\hline & going & & & go & & & \\
\hline & & & going & & & go & \\
\hline $19^{-24}$ & & $\begin{array}{l}\text { going } \\
\text { gone } \\
\text { goes }\end{array}$ & & & & & \\
\hline $25-30$ & $\begin{array}{l}\text { gone } \\
\text { goes }\end{array}$ & & & & & going & \\
\hline $3{ }^{1-}-36$ & & went & gone & & & & \\
\hline & went & & & going & & & \\
\hline $37-42$ & & & & gone & $\begin{array}{l}\text { go } \\
\text { going }\end{array}$ & & \\
\hline $43^{-5} \mathrm{I}$ & & & & $\begin{array}{l}\text { went } \\
\text { goes }\end{array}$ & & goes & goes \\
\hline & & & went & & & & went \\
\hline
\end{tabular}

${ }^{a}$ No other syntactic structures were acquired by the children during the study.

b Approximate number of weeks into study when form acquired.

available to them. For example, by $7^{-1} 2$ weeks into the study, gone, and go are used with no complement, yet gone is not used in many of the other structures used with go until later in development. By the end of the study, there is evidence that the children can use most forms of Go in most structures, but this suggests a gradual pattern of acquisition.

Input frequency and the order of acquisition of syntactic structure. To address the question of why children learn to use different forms of Go in some structures sooner than others, the input data were examined to investigate whether the frequencies of use of each form of $G o$ in each structure predicted their order of acquisition in the children's speech. The mean frequencies of use of each form in each structure in the input $(N=30: 5$ forms of $G o \times 6$ 
structures; $93 \%<0.80$ ) were compared with their mean rank order of acquisition in the children's speech. The rank order correlation between mean frequency of use in the input and mean order of acquisition in the children's speech was significant $(\rho=-0.78, d f=28, p>0.00 \mathrm{I})$, and shows that the order of acquisition of different forms of $G o$ in different structures in the children's speech reflects their frequency of use in the input.

\section{Semantic development}

The children's use of the verb Go was then examined with respect to the meanings encoded by each form to establish whether differences in the structures used with each form reflect differences in the semantics encoded. For each form of Go the utterances were categorized according to the meanings listed in Table 2.

Differential use of verb semantics. Only those meanings used by at least io of the children were examined. These were movement (I), belonging (2), disappearance (3), intent (4), encourage (5) and sound (6). However, 'encourage' is used only with go so this category was excluded from the following comparisons. Table 6 shows the mean proportional use of each

TABLE 6. The mean proportional use of each form of ' $G o$ ' in different semantic structures produced by $\mathrm{IO}^{+}$children

\begin{tabular}{|c|c|c|c|c|c|c|}
\hline & movement & belong & disappear & intent & sound & encourage \\
\hline go & $53 \cdot 3$ & I 9.4 & 0.3 & 10.4 & $2 \cdot I$ & 0.4 \\
\hline going & $49^{\circ} 9$ & $\mathrm{I} \cdot 4$ & 0.0 & $47 \cdot 2$ & 0.4 & o \\
\hline goes & $5 \cdot 8$ & $75^{\circ} \circ$ & 0.5 & 0.4 & $4 \cdot 7$ & o \\
\hline gone & I 3.9 & 0.3 & $82 \cdot I$ & $2 \cdot 2$ & 0 & 0 \\
\hline went & $77 \cdot 6$ & 0.0 & 0.0 & $\mathrm{I} \cdot 7$ & I $5 \cdot 5$ & ० \\
\hline
\end{tabular}

form of $G o$ with each meaning ( $N=30: 5$ forms of $G o \times 6$ structures; $95 \%$ $>0.70)$. The reported means suggest there are differences between forms of Go in terms of the meanings they are used to encode. The forms go, going, and went are commonly used to encode movement, goes is mainly used to encode belonging, and gone to encode disappearance. Going and, to a lesser extent, go are used to encode intent more frequently than the other forms.

The differences observed in the children's use of different meanings with the different forms of Go suggest that they may not be operating with a single lexical entry for the verb $G o$ but rather with a number of separate or partially related entries representing each form. To investigate this further, the mean proportional use of meanings with different forms of $G o$ in the input $(N=$ 25: 5 forms of $G o \times 5$ structures; $93 \%>0.70$ ) was compared with their mean proportional use in the children's speech. The correlation between the mean proportional use of meanings in the input and the children's speech was 
THEAKSTON ET AL.

significant $(r=0.93, d f=23, p<0.0 \mathrm{I})$ showing that there is a strong relationship between the use of different forms of $G o$ to express particular meanings in the input and in the children's speech.

Order of acquisition of verb semantics. Overall, the children's proportional use of meanings with different forms of $G o$ closely resembles adult use, but it is not clear if this provides an accurate representation of their knowledge over the whole year. The mothers use all forms of $G o$ with all meanings from the start of the study (except goes and went to encode disappearance), but the children may take time to acquire the meanings used with each form of $G o$. To examine this possibility, meanings were ranked according to the time period when they were acquired for each child. Table 7 shows the mean rank

TABLE 7. The mean rank order of acquisition of semantic structures in the children's speech ${ }^{\mathrm{a}}$

\begin{tabular}{|c|c|c|c|c|c|}
\hline $\begin{array}{l}\text { Weeks into } \\
\text { study }\end{array}$ & movement & belong & disappear & intent & sound \\
\hline \multirow[t]{2}{*}{ I-6 } & & & gone & & \\
\hline & $\begin{array}{l}\text { go } \\
\text { going }\end{array}$ & & & & \\
\hline \multirow{4}{*}{$\begin{array}{r}7-\mathrm{I} 2 \\
\mathrm{I} 3^{-\mathrm{I}} 8\end{array}$} & & go & & & \\
\hline & & & & go & \\
\hline & gone & goes & & & \\
\hline & & & & going & \\
\hline I 9-24 & & & & & go \\
\hline $25-30$ & went & & & & \\
\hline $3 \mathrm{I}-3^{6}$ & & & & gone & \\
\hline $37-42$ & & going & & & \\
\hline & & & & went & \\
\hline & goes & & & & \\
\hline & & & go & & \\
\hline $43^{-5} \mathrm{I}$ & & & & & going \\
\hline & & & & went & \\
\hline & & & goes (error) & & \\
\hline & & & & & goes \\
\hline
\end{tabular}

a No other semantic structures were acquired by the children during the study.

order of acquisition of meanings with each form of $G o(N=25: 5$ forms of Go $\times 7$ structures; $98 \%>0.70$ ) and the approximate time period between the start of the study and the acquisition of each form with each meaning.

There is a considerable delay between the first use of a meaning with one form of $G o$ and its use with other forms. For example, go and going are used to encode movement from the beginning of the study but the children do not use this meaning with gone and goes until I $3^{-1} 8$ and $37^{-42}$ weeks into the study, although they learn these forms much earlier. Even went, which is 
learned later than goes, is used to encode movement earlier. Similar patterns of development can be observed with respect to belonging, disappearance, intent and sound which suggests that the children's understanding of verb meaning may initially be restricted to individual forms of $G o$ and only slowly developing towards adultlike knowledge.

Input frequency and the order of acquisition of verb semantics. To address the question of why children learn to use different forms of Go with some meanings sooner than others, the input data were examined to investigate whether the frequencies of use of each form of $G o$ with each meaning in the input predicted their order of acquisition in the children's speech. The mean frequencies of use of each form with each meaning in the input $(N=25: 5$ forms of $G o \times 5$ structures; I $00 \%>0.80$ ) were compared with their rank order of acquisition in the children's data. The rank order correlation between mean order of acquisition in the children's speech and mean frequency in the input was significant $(\rho=-0.88, d f=23, p<0.00 \mathrm{I})$, and shows that the order of acquisition of different forms of $G o$ with different meanings in the children's speech reflects their frequency of use in the input.

Lexical specificity in the use of different syntactic structures with each verb form. Although the documented pattern of use of structures and meanings is consistent with a gradual pattern of acquisition, the apparently late acquisition of some structures or meanings with particular forms of $G o$ may reflect sampling limitations or the preferred forms of expression in the language. Therefore, we examined the extent to which PP, infinitival, and Wh-question structures show lexical diversity in the speech of the mothers and the children using matched samples of speech. If children's knowledge of the relation between forms of $G o$ is adultlike, the diversity of use of lexical forms in these structures with the different forms of $G o$ will be similar between mothers and children. If the children have a less unified representation of $G o$, their use of these structures is likely to be less diverse than use in the input.

\section{PP complements}

Lexical diversity of PPs in matched samples. The number of different prepositions used with each form of $G o$ was calculated for each mother and child. T-tests revealed that there were no differences between the mothers and the children in the number of different prepositions used with each form of $G o$ with the exception of gone, where the mothers used a significantly wider range of $\mathrm{PP}$ complements than the children $(t=-3 . \mathrm{I} 7, d f=20, p<0.0 \mathrm{I})$. However, the children produced a wider range of $\mathrm{PP}$ complements with $g o$ than with gone ( $g o M=\mathrm{I}_{\mathrm{I}} \cdot 3 ; S . D .=3 \cdot 3$; gone $M=4 \cdot 0, S . D .=\mathrm{I} \cdot 6$ ), which shows that the restricted use of PP complements with gone does not reflect a lack of lexical knowledge. Although by the end of the year, the children could use a similar range of different PP complements as their mothers with most 
THEAKSTON ET AL.

TA В LE 8. The mean rank order of acquisition of PP complements produced by $\mathrm{IO}^{+}$children with different forms of ' $G o^{\text {'a }}$

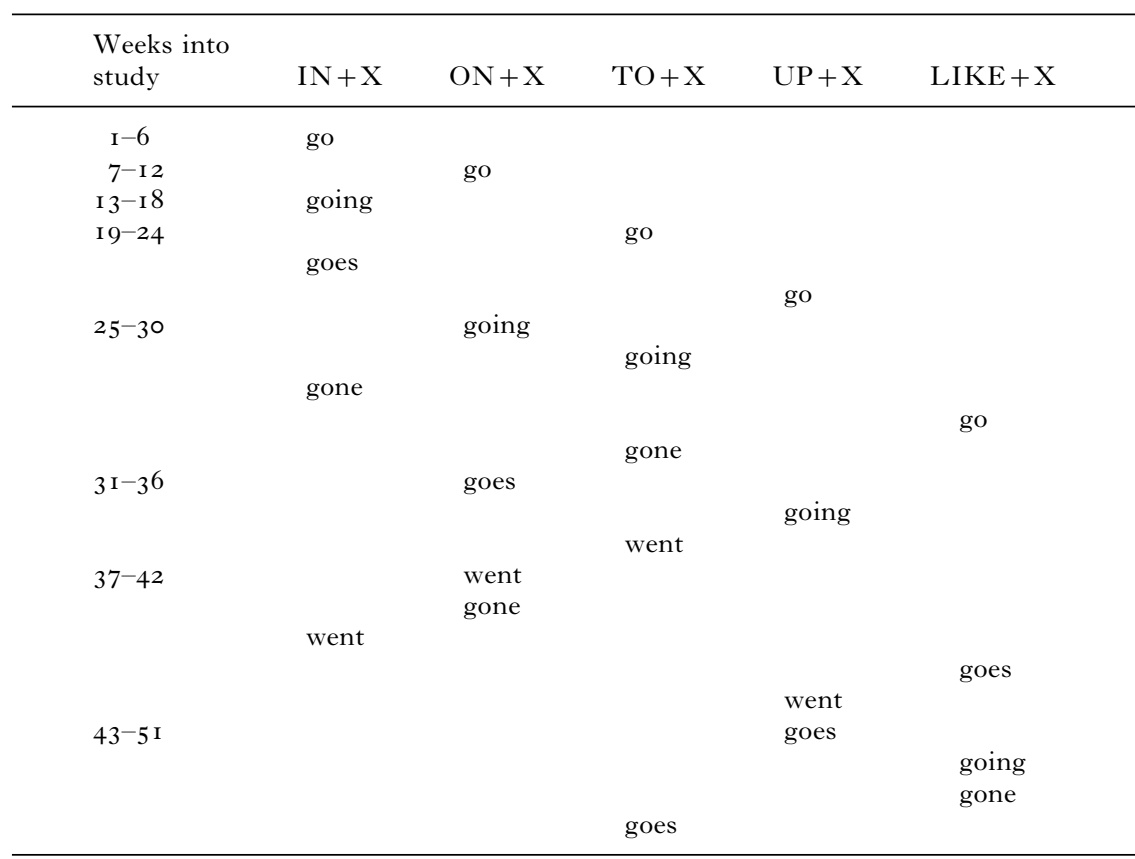

a No other PP complements were acquired by the children during the study.

forms of $G o$, they seemed unable to generalize their knowledge to the form gone.

Order of acquisition of PPs. Those PP complements used by at least 10 of the children (in $X$, on $X$, to $X, u p X$, like $X$ ) were ranked according to their order of acquisition with the different forms of $G o$ for each child. Table 8 shows the mean rank order of acquisition of each PP in the children's speech.

There were differences in the order and stage of acquisition of the PPs with different forms of $G o$, which suggests that the children's knowledge of PP complements may be tied to individual forms of $G o$ (e.g. on $+X$ is acquired earlier with going than with goes, but like $+X$ is acquired earlier with goes than with going). Although some prepositions were acquired later than others, this does not explain why there were differences in the use of some prepositions, once acquired, between forms of $G o$ (e.g. go in $+X$ vs. gone $i n+X)$.

Input frequency and the order of acquisition of PPs. The input data were examined to investigate whether the frequencies of use of each PP with each form of $G o$ in the input predicted their order of acquisition in the children's speech. The input data from the first eight tapes were searched for all 
THE ACQUISITION OF THE VERB 'GO'

TABLE 9. The mean number of different infinitival verb complements produced with each form of ' $G o$ '

\begin{tabular}{lcc}
\hline & $\begin{array}{c}\text { Mean no. of verb } \\
\text { complements produced in } \\
\text { the children's speech }\end{array}$ & $\begin{array}{c}\text { Mean no. of verb } \\
\text { complements produced } \\
\text { in the input }\end{array}$ \\
\hline go (incl. 'to') & $6 \cdot 6(S . D .=6 \cdot 8)$ & $\mathrm{I} \cdot 7(S . D .=\mathrm{I} \cdot 5)$ \\
going & $36 \cdot 8(S . D .=\mathrm{I} 6 \cdot 4)$ & $46 \cdot 2(S . D .=\mathrm{I} 5 \cdot 6)$ \\
goes & $0 \cdot 2(S . D .=0 \cdot 4)$ & $0 \cdot 2(S . D .=0 \cdot 4)$ \\
gone & $\mathrm{I} \cdot 2(S . D .=0 \cdot 4)$ & $2 \cdot 3(S . D .=\mathrm{I} \cdot \mathrm{I})$ \\
went & $0 \cdot 3(S . D .=0 \cdot 6)$ & $0 \cdot 8(S . D .=\mathrm{I} \cdot 0)$ \\
\hline
\end{tabular}

exemplars of the selected PPs and the frequency of each PP with each form of $G o$ was calculated. The mean frequencies of different PPs with different forms of $G o$ in the input $(N=25: 5$ forms of $G o \times 5$ PPs; $67 \%>0.60)$ were compared with their mean rank order of acquisition in the children's data $(N$ $=25: 5$ forms of $G o \times 5$ PPs; $53 \%>0.50)$. The rank order correlation was significant $(\rho=-0.89, \mathrm{df}=23 ; p<0.00 \mathrm{I})$, showing that the frequency of different PPs with different forms of $G o$ in the input is a good predictor of their order of acquisition in the children's speech.

\section{Infinitival complements}

For go, there were many instances in the children's speech where it was unclear whether the utterance should be classified as an infinitival complement of go, or as a coordinated structure where the conjunction and has been omitted (e.g. I go get that is ungrammatical and could mean either I'll go to get that or I'll go and get that). For purposes of comparison with the input, the children's data were searched for all complements of go produced with the infinitival marker to as these are the only forms that can be clearly interpreted as infinitives.

Lexical diversity of infinitival complements in matched samples. Table 9 shows the mean number of different infinitival complements produced with each form of $G o$ in the children's speech and in the input. T-tests revealed that the mothers produce a wider range of verbs with gone than the children $(t=-3.08, d f=20, p<0.0 \mathrm{I})$ whereas the children produce a wider range of verbs with $g o$ than the mothers $(t=2 \cdot 35, d f=20, p<0.05)$. The similarities between the mothers and children in terms of the number of infinitival complements produced with goes and went reflect the fact that very few complements are produced by either group with these forms of Go.

Order of acquisition of infinitival structures. As the mothers produce very few infinitival complements with go, it seems unlikely that the children have learned these forms directly from their use in the input. Instead, they may have learned a range of infinitival complements with going, and be 
THEAKSTON ET AL.

generalizing their use to go. The data were examined to determine the stage at which the children acquired the frames $g o+t o+V$ and going $+t o+V .{ }^{6} \mathrm{On}$ average, the 8 children who produced both frames acquired going + to $+V$ earlier than $g o+t o+V$ (going $+t o+V 25-30$, and $g o+t o+V 3 \mathrm{I}^{-} 36$ weeks into the study). The apparent generalization from going to go indicates that by this relatively late point in development the children recognise a phonological, semantic and/or distributional relationship between these forms. However, their restricted use of gone in infinitivals, in comparison with use in the input, suggests that they are unable to generalize their knowledge of infinitival complements from either going or go to gone. Thus, it appears that the children do not yet have a complete understanding of the relation between gone and other more frequent forms of Go.

Input frequency and the acquisition of infinitival complements. To investigate whether the frequency of use of different infinitival complements with different forms of $G o$ in the input might influence their order of acquisition in the children's speech, input data from the first eight tapes were examined and the frequency of use of each complement verb with each form of Go calculated.

- For go, of the ro mothers who produced infinitivals, only one verb (sleep) was produced by all io mothers and accounted for a mean of $86.4 \%$ (range $44 \cdot 4^{-100 \%} \%$ ) of go infinitivals. For Io children sleep was the first or second verb to be produced with go and accounts for a mean of $56.7 \%$ (range $0-100 \%$ ) of the children's go infinitivals.

- For going, the 25 most frequent verb complements, calculated across the mothers' data, were ranked for order of acquisition with going in the children's speech. The rank order correlation between mean frequency in the input and mean order of acquisition in the children was significant $(\rho=-0.82, d f=23, p<0.00 \mathrm{I})$, which suggests that the frequency of different verb complements with going in the input provides a good predictor of their order of acquisition in the children's speech.

- For goes, two different complement verbs were produced in the input and only one child produced goes in this structure. Seventyfive percent of the verb tokens in the input were accounted for by a single verb (sleep), the only verb acquired by that child.

- For gone four different complement verbs appeared in the input. All I I children produced this structure. One verb (sleep) accounted for the majority of uses in the input $(85.7 \%)$ and was the only verb acquired by 9 of the children (the remaining children produced just one other verb each).

[6] Acquisition was defined as the point at which a particular child produces two different verbs with a particular form of $G o$.

802 
- For went, four different complement verbs appeared in the input. Only two of the children produced infinitivals with went (one and two verbs only), but both acquired the verb see which accounts for $50 \%$ of infinitivals produced in the input.

Thus, the data suggest that (I) although the children may have productive use of the infinitival structure with going and go, their use of these forms seems to be influenced, initially at least, by the frequency of particular complement verbs in the input, (2) the children's production of infinitival structures with goes, gone and went is very limited (in the case of gone, their use is more limited than in the input), and may reflect lexical learning tied to high frequency verb complements used with each form in the input, and (3) there is little generalization between forms of $G o$ (with the possible exception of going and go at a relatively late stage in development).

\section{Wh-questions}

Wh-questions are interesting because the correct use of different Wh-words with different forms of $G o$ requires an understanding of the complex systems governing tense and agreement. Sentences with Wh-subjects mark tense on either the auxiliary, or the main verb, and therefore all forms of $G o$ can appear in simple questions of this type (e.g. What can go there?, What's going there?, What goes there?, What's gone?, What went here?). In contrast, most other Wh-questions mark tense on the auxiliary. Single clauses containing a finite verb and an auxiliary (e.g. Where's it goes?, Where's it went) are ungrammatical, therefore, the forms goes and went require the use of more complex sentence frames to appear in questions of this type (e.g. Where's it go?,' Where's it going?, Where's it gone? vs. Where do you think it goes?, Where do you think it went?). The issue to be addressed is to what extent children's early use of Wh-questions with different forms of $G o$ illustrates an ability to generalize knowledge across forms through an understanding of tense and agreement.

Lexical diversity of Wh-questions in matched samples. The children's data and the matched samples from the input were searched for all Wh-questions and the number of different Wh-words used with each form of $G o$ calculated. T-tests showed that the mothers produced a significantly greater number of different Wh-words with go, going, and gone than the children (go, $t=-4 \cdot 23$, $d f=20, p<0.00 \mathrm{I}$; going, $t=-2.54, d f=20, p<0.05$, gone, $t=-4.37, d f=$ $20, p<0.00 \mathrm{I})$. The similarities in the number of Wh-words produced with goes and went reflect the fact that neither the mothers nor children produced more than a mean of $\mathrm{I}_{4} 4 \mathrm{Wh}$-words with either form.

[7] In the utterance Where's it go?, the ' $s$ ' is assumed to be the cliticized remnant of does, i.e. Where does it go? 
THEAKSTON ET AL.

T АВLE го. The rank order of acquisition of Wh-questions with each form of ' $G o^{\text {'a }}$

\begin{tabular}{|c|c|c|c|c|c|c|c|c|}
\hline $\begin{array}{l}\text { Weeks into } \\
\text { study }\end{array}$ & where & what & who & which & how & why & whose & when \\
\hline $\mathrm{I}-6$ & gone & & & & & & & \\
\hline \multirow{5}{*}{$\begin{array}{r}7-12 \\
19^{-24} \\
3 I^{-}-36 \\
37^{-42}\end{array}$} & & & & & & & & \\
\hline & going & & & & & & & \\
\hline & & going & & & & & & \\
\hline & goes & & & & & & & \\
\hline & & go & & & & & & \\
\hline \multirow[t]{10}{*}{$43^{-5}$} & & & & & going & & & \\
\hline & & goes & & & & & & \\
\hline & & & & & $\begin{array}{l}\text { go } \\
\text { goes }\end{array}$ & & & \\
\hline & & & & & & gone & & \\
\hline & & & & & & go & & \\
\hline & & & $\begin{array}{l}\text { go } \\
\text { going }\end{array}$ & & & & & \\
\hline & & & & $\begin{array}{l}\text { go } \\
\text { going }\end{array}$ & & & & \\
\hline & went & & & & & & & \\
\hline & & & & & & & & $\begin{array}{l}\text { going } \\
\text { went }\end{array}$ \\
\hline & & & & & & & going & \\
\hline
\end{tabular}

a No other Wh-forms were acquired by the children during the study.

These differences in Wh-question use could reflect the children's lack of knowledge of particular Wh-words. Therefore, the mean number of different forms of Go produced with each Wh-word was calculated for the mothers and children who produced that Wh-word (and therefore know the Wh-word in question) to examine whether the mothers generalized use of each Whword across forms of $G o$ more than the children. The mothers produced a wider range of forms of $G o$ than the children with 6 of the 8 Wh-words examined, which is consistent with the suggestion that even when children have learned a particular Wh-word, they are less able to generalize their knowledge of that Wh-question across forms of $G o$ than the mothers.

Order of acquisition of Wh-questions. The children's data were ranked in terms of the order of acquisition of different Wh-words with different forms of Go. Table ıo shows the mean rank order of acquisition of Wh-words with each form of $G o(N=40: 5$ forms of $G o \times 8$ Wh-words; $78 \%>0.50)$.

Table ro shows that although the children acquired different Wh-words at different stages in development, they did not produce given Wh-words with different forms of $G o$ at the same stage of development once those Wh-words were acquired (e.g. where is acquired early with gone but not until later in development with other forms of $G o$ ). Of particular interest is the slot-and-

804 
frame appearance of the children's where questions. Means of $8 \mathrm{r} \cdot 0 \%$ (S.D. $=\mathrm{r} 6 \cdot 8), 76 \cdot 0 \%(S . D .=28 \cdot 8)$ and $98.5 \%(S . D .=2 \cdot 0)$ of the children's where questions with go, going and gone respectively consist of the two frames Where $X V$ ? (i.e. Where (did/does etc.) $X V$ ?) and Where's $X V$ ?. Although these frames may have been acquired separately from the input, the children's use of Where questions with goes suggests that they may have made some connection between forms of $G$ o. Of the five children who produce where questions with goes $(M=2 \cdot 2$ utterances; range $\mathrm{I}-4)$, three only produce the frame Where $X$ goes? while the other two only produce the frame Where's $X$ goes?. The use of either frame is ungrammatical because both require a nonfinite form of Go. Although Where $X$ goes? could be acquired from embedded clauses (e.g. Is that where it goes?), those children who produce Where's $X$ goes? must be using language productively as these forms are not present in the input. However, where questions with goes are produced very late in the study (37-42 weeks), and all five children produce where questions with go, going and gone before they produce incorrect goes questions. This suggests that only after children have learned a series of separate frames associated with different forms of $G o$ from the input are they able to abstract the construction Where's $X V$ to generate new utterances not learned directly from the input. Moreover, although by this late stage in development the children may have recognized a relation between forms of $G o$, it is clear that they have yet to develop an understanding of how to mark tense correctly.

Input frequency and order of acquisition of Wh-questions. The input data were examined to establish whether the frequency of different Wh-words with different forms of $G o$ predicted their order of acquisition in the children's speech. The mothers data from the first 8 tapes were searched for all Wh-questions and the frequency of use of each Wh-word with each form of $G o$ calculated. The mean frequencies of use of different Wh-words with different forms of $G o$ in the input $(N=40: 5$ forms of $G o \times 8$ Wh-words; $73 \%>0.60)$ were compared with their rank order of acquisition in the children's speech. The rank order correlation was significant $\left(\rho=-0 \cdot 6_{5}, d f\right.$ $=38, p<0.00 \mathrm{I})$ suggesting that the frequency of use of different Wh-words with different forms of $G o$ in the input is a good predictor of their order of acquisition in the children's speech.

The above analyses, based on a comparison of the use of individual lexical forms in specific structures in the children's speech and matched samples from the input, show that even when sample size and knowledge of lexical forms were controlled, the children showed less evidence of operating with system-wide grammatical knowledge than their mothers. They used fewer $\mathrm{PP}$ and infinitival complements with gone, and fewer Wh-words with different forms of $G o$ than were found in the input. Interestingly there was some evidence of generalization between forms of $G_{0}$ (the use of Whquestions with goes and infinitivals with go), but crucially this occurred 
relatively late in development, and was restricted to specific structures. The late errors observed in the production of Wh-questions with goes suggest that although children may have recognized a phonological similarity between goes and other forms of $G o$, they have not yet developed a full understanding of the grammatical role of this form. ${ }^{8}$

\section{DISCUSSION}

The present study aimed to provide a detailed picture of the acquisition of the verb $G o$, and to examine the level of syntactic generality available to children between the ages of 2 ; 0 to 3 ; 0 . A general analysis comparing the children's data for the whole year with the input data suggests that their use of $G o$ is largely adultlike. However, a lexical analysis taking a developmental approach suggests that the children may not initially operate with a single, adultlike representation of the verb $G o$ in the lexicon.

With respect to the predictions derived from generativist and constructivist accounts, the data suggest the following. First, the comparison of lexical diversity in the children's speech and the input showed that in specific structures, with individual forms of $G o$, the children's use of lexical forms was more limited than that observed in the mothers' data, even though there was evidence that the children had acquired the relevant forms. These results favour a constructivist interpretation of the data.

Second, the children did not produce specific structures, meanings, or even lexical items (e.g. individual prepositional phrases) across forms of Go. Instead, the order in which the structures and meanings of $G o$ were acquired reflected their relative frequencies in the input. These results can be interpreted either as implicating a causal role for the input in determining the pattern of acquisition, or as a reflection of sampling issues and the children's sensitivity to preferred forms of expression in English. Finally, the pattern of errors that suggests a limited understanding of tense and agreement is not

[8] One reviewer expressed concern that other errors might provide evidence for earlier integration of forms of Go. However, an analysis of the children's errors with the verb Go shows that the vast majority of errors $(87 \%)$ consist of the use of an auxiliary form predominantly contracted 's' with the form go (e.g. he's go to look around), with occasional use with finite forms goes (e.g. that one's goes there) and went (e.g. he's went over his wheels). These errors seem to reflect the children's developing knowledge of subject-verb agreement rather than their knowledge of the relation between different forms of $G o$, especially given that these types of errors are also observed with other verbs in the children's speech. Other errors consist of the use of finite verb forms in Wh-questions where finiteness should be marked by an auxiliary, and negation errors where finiteness is incorrectly marked or omitted (don't go/goes). Overall, the errors observed with Go seem to reflect the children's lack of knowledge of the appropriate way to mark tense in different argument structures, suggesting that their knowledge of the relation between forms of $G o$ is not fully integrated. 
specifically predicted by generativist approaches, whereas constructivist approaches predict that these types of errors will occur as children relate the different forms of $G o$ but sometimes enter them incorrectly into constructions learned with other forms.

While the data are open to alternative interpretations, taken as a whole they suggest that children's early use of different forms of $G o$ is lexically-specific, and that the acquisition of the different structures and meanings associated with $G o$ occurs gradually and at different rates with different forms of $G o$. Moreover, it appears that the children are not operating with an adultlike representation of $G o$ even by age 3;0, which suggests that children's linguistic systems remain organized around individual lexical items well beyond the earliest stages of language acquisition. Although we favour a constructivist interpretation of the data, in most of these analyses, we cannot differentiate empirically between generativist and constructivist perspectives. It is clear that the increasingly lexicalist nature of generativist accounts of language acquisition, and their emphasis on competence rather than performance may mean that ultimately, we are unable to differentiate empirically between these approaches.

These data raise questions for both generativist and constructivist accounts of language acquisition. If generativist theories are to explain these data, we need explicit predictions as to how and when children build verb paradigms, and to relate this process to the acquisition of tense and agreement marking. Although many generative theorists would claim that building a unified verb paradigm for $G o$ will take time, many would also assume that children have a knowledge of tense and agreement marking from very early in development. These two apparently contradictory claims are not, to our knowledge, currently integrated in any detail in generative theories of acquisition. Second, generativists will need to develop new ways to test children's linguistic competence if they wish to assume that sampling issues or performance factors reflecting preferred forms of expression can explain the children's lack of use of some structures and meanings with different forms of Go. The traditional methods used to test children's grammatical competence, for example, examining the pattern of subject case marking with finite and nonfinite verbs, are also open to alternative interpretations, because the patterns of language use that generativists assume reflect an abstract grammar are often predicted by constructivist accounts because they reflect the patterns of language children hear.

However, to explain these data, constructivists also need to characterize the process of acquisition in considerably more detail. For example, a lack of evidence for the abstract grammatical representations, assumed by generativist approaches to underpin children's early speech, does not mean that children only have lexically-specific constructions associated with different forms of Go. Rather, there will be points in development where they 
have neither very simple formulae, nor an adultlike grammar. The apparent generalization of use of infinitival structures with going and go, and where questions with goes, may relate to the abstraction of schemas (e.g. $V$ to $V$, Where's $X V$ ?) from previously learned lexically-specific frames, perhaps on the basis of distributional, phonological and/or semantic similarities. However, we know very little about the precise circumstances under which these abstractions are made, nor about the relative influences of input frequency compared with semantic, distributional, or phonological similarity in supporting abstraction. In this study, input frequency seemed to play a central role in the acquisition process, irrespective of the specific relations between forms of $G o$ in terms of the structures in which they appear, their meanings, or their phonological form. One possibility, however, is that the different meanings associated with $G o$ are organized around a prototype (e.g. movement), and that the closer different meanings are to the prototype, the easier they are for children to acquire and integrate into their existing linguistic system. Similarly, some forms may be so different in meaning to the prototype that they are stored separately, even in the adult grammar. Another possibility is that forms that share phonological content (go/going/ goes/gone) will be integrated earlier than forms that involve suppletion (went). However, we would need to differentiate the relative roles of frequency and similarity in meaning or phonological form in much more detail to better understand how abstraction in the system occurs.

A second problem for constructivist accounts lies in providing a more detailed characterization of adult linguistic representations. These data are compatible with usage-based models of adult language (Langacker, I987; Croft, I999, in press $a$ ), in which linguistic knowledge is organized around constructions rather than the abstract grammatical concepts that form the basis of generativist models. Usage-based models assume that adults store linguistic information at a number of levels, from the lexically-specific to the more abstract, and frequency of use determines whether utterances are stored as linguistic wholes or constructed from more abstract units (Bybee, I 998). Therefore, in the adult system, the frequency of use of forms of Go with different structures and meanings will influence whether they are stored as lexically-specific constructions, or generated from more abstract schemas. Thus, adults as well as children are thought to use lexically-based schemas to produce many of their utterances. However, because the extraction of abstract schemas that provide links between lexically-specific schemas is thought to be based on accumulating linguistic experience, and to take place in development, children will initially have only highly specified constructions based around high frequency lexical items. The difficulty is that without a detailed characterization of how different levels of information are represented in the adult system, we know very little about how much 
development is needed in children's systems to reach an adultlike knowledge of grammar.

Aside from the limitations outlined above in providing a satisfactory account of these data, we suggest that researchers should be cautious in crediting children with an abstract knowledge of tense marking. Although only one verb was examined, Go is the most frequent verb, and goes the most frequent 3 rd person singular verb (excluding the copula) produced by 9 of the I I children (2nd most frequent for 2 children), accounting for a mean of $38 \cdot 2 \%$ (range $12 \cdot 9-72 \cdot 3 \%$ ) of all 3 rd person singular verb use, and is arguably the verb about which they know the most. Yet these data suggest that children's knowledge of the relations between different forms of Go may be less abstract than is often assumed (based on an analysis of over 9000 uses). It is therefore unclear what conclusions regarding children's grammatical knowledge should be drawn from the sporadic use of other 3 rd person singular forms many of which are produced just once in the speech of individual children. If go and goes are initially learned as unrelated lexicallybased constructions, this would count as evidence against an 'Optional Infinitive' interpretation of early verb use (Wexler, I994) because it is unclear in what sense the use of tense can be said to be 'optional'.

In conclusion, the detailed picture of early verb use documented in this study is broadly consistent with a constructivist approach to early language acquisition. The data suggest that children build up adultlike grammatical knowledge by beginning with specific lexical frames and gradually moving towards more abstract schemas. However, much more work is needed to establish how children form schemas which operate across larger groups of lexical items. In addition, this study has demonstrated the difficulties associated with attempting to derive empirically testable predictions that differentiate between generativist and constructivist approaches to early language use. Where it is impossible to differentiate empirically between the two positions, it is a matter of theoretical preference which theory is adopted. Further analyses incorporating a wider range of verbs are required to enable us to better understand the nature of children's early understanding of tense and agreement and the interaction between their knowledge of these systems and their use of syntax. It appears, however, that by examining the input with respect to individual lexical items rather than in terms of abstract grammatical categories, it is possible to uncover relationships between children's language use and the language they hear which raises interesting questions as to the precise role of the input in acquisition (Lieven, I994; Pine, I 994; Rowland \& Pine, 2000; Theakston et al., 2001). 


\section{REFERENCES}

Akhtar, N. \& Tomasello, M. (I 997). Young children's productivity with word order and verb morphology. Developmental Psychology 33, 952-65.

Bloom, L., Miller, P. \& Hood, L. ( I 975). Variation and reduction as aspects of competence in language development. In A. D. Pick (ed.), Minnesota Symposia on Child Psychology, Vol. 9. Minneapolis: University of Minnesota Press.

Bybee, J. (1995). Regular morphology and the lexicon. Language and Cognitive Processes Io, $425^{-5}$.

Bybee, J. (1998). The emergent lexicon. In M. C. Gruber, D. Higgins, K. S. Olson \& T. Wysocki (eds), Papers from the 34th annual meeting of the Chicago Linguistics Society, Part $2:$ the panels. Chicago: Chicago Linguistics Society.

Bybee, J., Perkins, R. \& Pagliuca, W. (I994). The evolution of grammar. Chicago: The University of Chicago Press.

Bybee, J. \& Scheibman, J. (I999). The effect of usage on degrees of constituency: the reduction of don't in English. Linguistics 37, 575-96.

Clark, E. ( 1 978). Discovering what words can do. In D. Farkas, W. Jacobsen \& K. Todrys (eds), Papers from the parasession on the lexicon. Chicago: Chicago Linguistic Society.

Croft, W. (1998). Linguistic evidence and mental representations. Cognitive Linguistics 9, I 5 I -73 .

Croft, W. ( I 999). Some contributions of typology to cognitive linguistics (and vice versa). In T. Janssen \& G. Redeker (eds), Cognitive linguistics : foundations, scope and methodology. Berlin: Mouton de Gruyter.

Croft, W. (in press a). Radical construction grammer : syntactic theory in typological perspective. Oxford: Oxford University Press.

Croft, W. (in press $b$ ). Lexical rules vs. constructions: a false dichotomy. In H. Cuyckens, T. Berg, R. Dirven \& K. Panther (eds), Motivation in language: studies in honous of Guenter Radden. Amsterdam: John Benjamins.

Goldberg, A. E. (I 995). Constructions : a construction grammar approach to argument structure. Chicago: The University of Chicago Press.

Langacker, R. W. (1987). Foundations of Cognitive Grammar, Vol. I: Theoretical Prerequisites. Stanford, California: Stanford University Press.

Langacker, R. W. (I99I). Foundations of Cognitive Grammar, Vol. 2: Descriptive Application. Stanford, California: Stanford University Press.

Levin, B. \& Hovav, M. Rappaport (I995). Unaccusativity: at the syntax-lexical semantics interface. Cambridge, MA: MIT Press.

Lieven, E. V. M. (1994). Crosslinguistic and crosscultural aspects of language addressed to children. In C. Gallaway \& B. Richards (eds), Input and interaction in language acquisition. Cambridge: CUP.

MacWhinney, B. (2000). The CHILDES Project: tools for analyzing talk. Hillsdale, NJ: Erlbaum.

MacWhinney, B. \& Snow, C. ( 1990). The Child Language Data Exchange System: an update. fournal of Child Language $\mathbf{1 7}, 457-72$.

Marcus, G., Pinker, S., Ullman, M., Hollander, M., Rosen, T. \& Xu., F. (1992). Overregularisations in language acquisition. Monographs of the society for research in child development (Serial no. 228, Vol. 57).

Naigles, L. R. \& Hoff-Ginsberg, E. (I998). Why are some verbs learned before other verbs? Effects of input frequency and structure on children's early verb use. Fournal of Child Language 25, 95-1 20.

Pine, J. M. (I 994). The language of primary caregivers. In C. Gallaway \& B. Richards (eds), Input and interaction in language acquisition. Cambridge: CUP.

Pine, J. M., Lieven, E. V. M. \& Rowland, C. F. (1998). Comparing different models of the development of the English verb category. Linguistics 36, 807-30.

Pinker, S. (1984). Language learnability and language development. Cambridge, MA: Harvard University Press.

8 Iо 


\section{THE ACQUISITION OF THE VERB 'GO'}

Pinker, S. (1989). Learnability and cognition: the acquisition of verb-argument structure. Cambridge, MA: Harvard University Press.

Pinker, S. (r 994). The language instinct. London: Penguin.

Radford, A. ( I 990). Syntactic theory and the acquisition of English syntax. Oxford: Blackwell.

Rowland, C. F. \& Pine, J. M. (2000). Subject-auxiliary inversion errors and wh-question acquisition: 'what children do know?'. Fournal of Child Language 27, I 57-8 I.

Theakston, A. L., Lieven, E. V. M., Pine, J. M. \& Rowland, C. F. (200I). The role of performance limitations in the acquisition of verb-argument structure: an alternative account. Fournal of Child Language 28, I 27-52.

Tomasello, M. (I 992). First verbs : a case study of early grammatical development. Cambridge: CUP.

Wexler, K. (r 994). Optional Infinitives, head movement and the economy of derivations. In D. Lightfoot \& N. Hornstein (eds), Verb movement. Cambridge: CUP.

Wexler, K. (I998). Very early parameter setting and the unique checking constraint: a new explanation of the optional infinitive stage. Lingua ro6, 23-79. 